\title{
Effect of COVID-19 on the Performance of Grade 12 Students: Implications for STEM Education
}

\author{
Edgar John Sintema ${ }^{1^{*}}$ \\ ${ }^{1}$ PhD Candidate, School of Doctoral Studies, Universidad de Valladolid, SPAIN
}

Received 13 March 2020 • Accepted 6 April 2020

\begin{abstract}
With all learning institutions pre-maturely closed on 20 March 2020 and all citizens advised to self-isolate in a bid to control the spread of COVID-19, it was hypothesized that COVID-19 would negatively impact on the performance of students in the 2020 Grade 12 national examinations vis-à-vis mathematics, science and design and technology subjects. An observed steady increase in the number of COVID-19 confirmed cases and the low levels of technology use in secondary schools in Zambia due to limited technology resources signifies a very difficult period in a young country which has just rolled out a nation-wide implementation of STEM education, This study collected data from three teachers at a public secondary school in Chipata District of Eastern Province in the Republic of Zambia. The Head of Department for Mathematics, the Head of Natural Sciences Department and one science teacher were interviewed. Semi-structured interviews via mobile phone were used to collect views of what these specialists thought would be the COVID19 effects on the general performance of students in their subject areas. Results of this study revealed that there is likely to be a drop in the pass percentage of secondary school students in this year's national examinations if the COVID-19 epidemic is not contained in the shortest possible time considering that the school academic calendar was abruptly disturbed by the early untimely closure of all schools in the country.
\end{abstract}

Keywords: COVID-19, STEM subjects, mathematics education, Zambia

\section{INTRODUCTION}

Around mid-March 2020, the Zambian government through the Minister of Health announced at a press briefing that all schools, colleges and universities would close indefinitely on Friday, 20 March 2020 amid fears of the Coronavirus (COVID-19) outbreak that had reportedly ravaged most parts of China, United States of America, Italy, Spain and other parts of Europe and Africa. This meant that secondary school students in most public and private schools ended Term 1 of the academic year 2020 without sitting for their end-of-term tests as many public and private schools administer assessment tests at the end of each of the three terms of the academic year.

\section{About COVID-19}

There is currently little or no literature on COVID-19 in relation to educational studies. The only literature available is directly related to medical studies (Chinazzi et al., 2020; Hopman, Allegranzi, \& Mehtar, 2020; Kraemer et al., 2020; Wu \& McGoogan, 2020; Zu et al., 2020). This is not because education is not directly affected by the effect of the COVID-19 epidemic but rather because studies in education rarely incorporate effects of disease on the effective provision of education to learners across the globe. The rate at which COVID-19 has rapidly been spreading has made every sector of human life to immediately feel its impact.

Medics are in the laboratories trying to find a medical solution to this epidemic. Economists are working on ways of managing the economic effect of this epidemic on country economies because businesses are closing down every day and there are restrictions on human mobility within and across boarders (Kraemer et al., 2020). A disease which appeared in the Chinese region of Wuhan surprisingly spread so fast across China and other parts of the world (Wickramasinghe et al., 2020). 


\section{Contribution to the literature}

- $\quad$ Research study investigated potential effects of COVID-19 on STEM education in Zambia.

- The study highlights the Zambian government response to COVID-19 by closing schools as an intervention measure to protect school children from the risk of contracting and spreading COVID-19.

- The study highlights how COVID-19 is likely to affect national examination results for the 2020 academic year.

- The study proposes suggestions for catching up on lost time in the academic calendar.

With news of increased number of cases of COVID-19 around the world it was legitimately reasonable for the government of Zambia to start worrying and putting measures in place that would prevent any form of COVID-19 outbreak in the country.

Sadly, at the time of writing this paper the Ministry of Health in Zambia had announced the death of one COVID-19 victim out of the reported 39 cases. This justifies government abrupt closure of all schools on $20^{\text {th }}$ March 2020. The government of Zambia has so far managed to contain the spread of COVID-19 with timely intervention measures that included restricted inflow of flights from outside, countrywide sensitization programs and daily updates by Ministry of Health officials. In fact, on 2 April 2020 Zambia had not recorded any new case of COVID-19.

\section{COVID-19 and STEM Education in Zambia}

The untimely closure of secondary schools was a positive response by government to protect school going children from possible risks of contracting COVID-19 because school environments are places where hundreds of students meet, and this makes them dangerous places where disease can rapidly spread. Many low- and middle-income countries have lamented the devastating economic effects that will come with COVID-19 as many economic drivers will be run down. However, little or nothing has been said about COVID-19 effects on education, particularly its effects on the performance of secondary school students who will be sitting for the national examinations in November 2020 and General Certificate Examination (G.C.E) candidates who will write their examinations in August 2020.

Thus, the purpose of this study was to report on the views of teachers of mathematics and science on the likely effects of COVID-19 on STEM education vis-à-vis performance of students in STEM subjects. This study is therefore important in that it provides information to the Ministry of Education to step up its preparedness to contain effects of COVID-19 on the education systems. It is also crucial because the results could be used by educationists in other contexts in their plans to prepare for combarting effects of the epidemic on their own education systems. The study is also significant to educational research as it contributes valid and important literature to the field of mathematics education that researchers could use to support future studies related to COVID-19 and education in general.

Zambia operates a trimester education system for all secondary schools. In this system students in examination classes like Grades 9 and 12 have about 13 weeks of learning each term. However, planned and unplanned activities usually make it impossible for these students to have a smooth academic year purely dedicated to learning and preparing for examinations which come in November of each year. Planned activities that affect the school calendar include sporting activities like athletics which usually come in term one and ball games which come in term two. Unplanned events include health related occurrences like COVID-19 that force government to close schools in order to save life. In the two cases that would affect the school calendar it is the unplanned events that have a farreaching damaging effect.

In the current situation the outbreak of COVID-19 forced the government of Zambia to close all schools and encouraged all citizens to self-isolate to curb the spread of the epidemic. This closure meant school going children losing close to three weeks of learning time in term one of 2020 with the re-opening date not known. Thus, the impact of this epidemic will strongly be felt by General Certificate Examination (G.C.E) candidates whose examinations are usually written in July/August of each year.

Their preparation for examinations has been adversely affected by the country wide self-isolation. Similarly, Grade 12 students who will be writing their final examinations in November have also been negatively affected by the loss of contact hours especially that the country does not have a well-developed elearning platform (Phiri \& Sintema, 2018) for schools that can cushion the loss of learning time. In the third term of the academic year 2020 teachers will be panicking trying to cover the syllabus.

As a result, STEM subjects will suffer the most because the country is already struggling to improve performance in these subjects. For Zambia which has been recording low pass rates in STEM subjects (Mathematics, Science, Design \& Technology), the effects of COVID-19 will most likely affect the rollout of the STEM curriculum which started early 2020 and the overall performance rates in Mathematics, Science and Design \& Technology subjects. 
Table 1. Trends analysis of performance of Grade 12 students in STEM subjects at a public school in Chipata District: adapted from Chipata Day secondary School results analysis report for 2020

\begin{tabular}{lccc}
\hline Subject & Performance (\%) in 2018 & Performance (\%) in 2019 & Percentage rise/drop \\
\hline Mathematics & 40.6 & 54.5 & +13.9 \\
Biology & 64.6 & 69.9 & +5.3 \\
Science & 61 & 60.4 & -0.6 \\
Pure Physics & 100 & 90.9 & -9.1 \\
Pure Chemistry & 100 & 100 & 00 \\
Design \& Technology & 100 & 100 & 00 \\
Computer Studies & 48.1 & 80.8 & +32.7 \\
\hline
\end{tabular}

Data collected from one public school in Chipata District shows that the pass rate of at Grade 12 level in national examinations has been on a steady increase, a situation which is pleasing. A look at the examinations results for the 2018 and 2019 academic years shows improvement in STEM subjects' performance (Table 1). Computer science and mathematics recorded significant improvements in performance levels with $32.7 \%$ and $13.9 \%$ rise in pass rate respectively while pure chemistry and design and Technology maintained a $100 \%$ pass rate over a two-year period. However, science recorded a small percentage drop in performance with pure physics posting quite a significant drop.

With the school putting in measures to maintain the maximum pass rate in Design \& Technology and pure chemistry, and interventions to induce a rise in other subjects, COVID-19 has emerged to be an obstacle and raises fears that the school may experience a drop in overall performance this academic year.

\section{METHODOLOGY}

This study employed a qualitative design (Creswell, 2017) using a case study approach. Three cases were studied throughout this study whose views are presented in the results section.

\section{Participants}

Interview data was collected from three teachers at a public secondary school in Chipata District of Eastern Province in Zambia. Of the three, one was the Head of Mathematics Department and one was the Head of the Natural Sciences Department. The third participant was a science teacher. The criteria for selection of the participants was defined by (i) being a secondary school teacher of either mathematics or any of the science subjects namely biology, chemistry or physics (ii) having 12 years teaching experience or more in their professional area of expertise, (iii) possessing basic knowledge of Coronavirus (COVID-19) disease from any source (knowledge from social media like Facebook, radio or television. World Health Organization updates, local updates from Ministry of Health). Following this criteria, four individuals were purposefully selected to participate in the study, but one withdrew before the interviews were even conducted.

\section{Instrumentation}

An interview protocol was developed by the author of this paper. The interview protocol initially comprised ten semi-structured questions. It was then given to two experts in mathematics education for determination of face validity and clarity of the items. The experts agreed on seven of the initial ten items. Thus, three items on which disagreement of experts was recorded were removed from the final version of the instrument. The final version of the instrument was then piloted with one mathematics teacher and his comments regarding the clarity of the questions were sought. His positive comments were noted, and no further item was removed from the final version.

\section{Data Collection and Analysis}

Interviews were conducted via telephone because there was a nation-wide call for self-isolation and social distancing of all citizens. The telephone interviews were recorded using a phone call recording application which was downloaded from play store of the Android phone which was used for this purpose. The phone interviews lasted twenty minutes each on average. They were transcribed and analyzed using constant appropriate qualitative data analysis techniques. Transcription and coding of data was performed by the researcher and one other independent person to avoid bias. All forms of discrepancies and inconsistencies were discussed and harmonized. Participants were asked to read the transcripts and to confirm that the transcription represented their views. This was done to increase the validity and reliability of the data.

\section{RESULTS}

Results of the telephone interviews conducted with mathematics and science teachers indicate that there will be a likely drop in the performance levels of both G.C.E candidates and Grade 12 internal candidates in this year's examinations. This is most likely to be caused by reduced contact hours for learners to the extent that they will largely not be able to consult teachers on the difficulties they encounter during their individual studying time. When asked how CVID-19 will affect performance in science subjects, the science teacher lamented lack of contact hours. The Head of Natural 
Sciences Department explained how these candidates will be affected with regards to school based practical assessment.

Interviewer: How do you think will the outbreak and effects of COVID-19 affect the performance of G.C.E candidates in science in the forthcoming July/August examinations?

Science Teacher: In fact, it is not just G.C.E candidates that will be affected. Even internal candidates will be affected. Automatically it will affect G.C.E candidates in the sense that many of them will not have access to coaching by teachers. It is likely that they are going to reach [examination time] August with very little contact with a teacher. That will automatically affect them negatively. In fact, G.C.E candidates are already deprived because they do not attend regular classes. They entirely depend on private tuitions for their examination preparations.

Head of Natural Sciences Department: G.C.E candidates do their own individual learning, but they receive school based practical assessment from schools. Looking at the remaining time before their exams and considering the new guidelines that we have just received; we are supposed to give them four practical assessments in Biology according to Examinations Council of Zambia (ECZ) guidelines. But because of limited time we are likely to give less than the required number of practical assessments. This will lead to poor performance.

In agreeing with his colleague, the mathematics teacher alluded to fears by teachers to teach and learners to learn due to self-isolation.

Interviewer: How do you think the outbreak and effects of COVID-19 will affect the performance of G.C.E candidates in mathematics in the forthcoming July/August examinations?

Head of Mathematics Department: G.C.E candidates are usually helped with [private] tuitions by teachers which cannot take place at the moment because of the self-isolation. Teachers are afraid to teach and learners are afraid to learn in such kind of an environment. Secondly, I think that if COVID-19 cases continue increasing, the G.C.E examinations are likely not to be conducted at the scheduled time.

When asked whether the Grade 12 internal candidates whose examinations usually take place in November will be affected, the mathematics teacher emphatically stated that the effect started with nonadministration of end-of-term tests for term one due to the unexpected closure of schools.

Interviewer: How do you think the outbreak and effects of COVID-19 will affect the performance of grade 12 internal candidates in mathematics in the forthcoming November examinations?

Head of Mathematics Department: Before schools closed, pupils were geared that in two- or three-weeks time they would be wring their end-of-term exams, a thing which did not take place. This affected them psychologically and their preparation for the exam was also affected. In terms of studying, pupils study effectively when they are able to consult their teachers on areas of need. With this closure of schools, it has become difficult for them to get explanations from teachers where they encounter difficulties during their individual study sessions at home. Basically, their studying schedules have been greatly affected since they cannot attend compulsory school organized prep.

The science teacher talked about different learning abilities of pupils which will be affected in different ways depending on the strategies and interventions employed by the teachers in preparing them for national examinations. The Head of Natural Sciences Department expects the scenario to be similar to that of the G.C.E candidates.

Interviewer: How do you think the outbreak and effects of COVID-19 will affect the performance of Grade 12 internal candidates in science in the forthcoming November examinations?

Science Teacher: They will be negatively affected. As you know, pupils have different learning abilities. Some are slow learners while others are fast learners. Some pupils are able to grasp [concepts when they read] on their own while others are heavily dependent on the explanations by a teacher in class. So, with this closure of schools with the re-opening date which has remained unknown some pupils have completely dumped their books and others may even be thinking that national exams will even be postponed. In short, learners will have few contact hours with their teachers this academic year. Teachers are likely to embark or crush programmes to match the limited available time in the coverage of the syllabus. Such programmes have the potential to negatively affect slow learners. Most likely slow learners will be disadvantaged.

When asked about the potential effects of COVID-19 of the on-going improvement of results in the Natural Sciences department, the science teacher feared that the 2020 examination results are likely to post a drop in overall performance of pupils. However, the Head of Natural Sciences expects to maintain results if the COVID-19 epidemic is contained by end of April 2020.

Interviewer: When I looked at the trends analysis for the 2018 and 2019 national examination results, I observed that the Natural Sciences department recorded improved results with a $100 \%$ pass rate in pure chemistry. With the threats that COVID-19 poses 
do you think that you will be able to maintain or even improve on this good performance as a department?

Science Teacher: Though I cannot quantify the effect, what I think is that COVID-19 effects will trigger a drop in the performance. It will have a negative effect which will see a downward trend in the results. I do not expect that we are going to improve or maintain where we are at the moment. If COVID-19 will cause any delay in the opening of schools for Term 2 then the impact will be significant.

Similarly, the mathematics teachers expressed fear that the upward trend in the mathematics results would suffer a setback if the COVID-19 epidemic is not contained quickly.

\begin{abstract}
Interviewer: Considering the mathematics department where you are currently acting as Head of Department, a trends analysis of for the 2018 and 2019 national examination results showed a steady improvement in the Grade 12 results. Do you have any fears that with the effects of COVID-19 the results in your department will be affected this year?
\end{abstract}

Head of Mathematics Department: That fear is very much there. Like I said earlier, the commitment of a child to academics in the absence of a teacher is reduced. Only few pupils can study independently without the involvement of a teacher. As such, we fear that results will be negatively affected because pupils are now doing things on their own without any guidance by the teacher.

When asked about appropriate strategies that need to be put in place to help mitigate the effects of COVID-19 on mathematics and science education the science teacher focused on interventions that he thinks should be put in place by Ministry of General Education while the Head of the Natural Sciences Department focused on school based interventions.

Interviewer: What strategies will your department employ to mitigate negative effects of COVID-19 which will help learners to prepare adequately for their final examinations?

Science Teacher: Everything depends on what the Ministry of General Education will do. The Ministry of Education should compensate the lost time by shortening the [August] holiday. The examinations timetable can be rescheduled. G.C.E exams can be pushed to late August while the Grade 12 national exams can be moved to December to give teachers and pupils time to cover the syllabus.

Head of Natural Science Department: We hope to adjust our teaching in order to protect our good results. We hope to see some teachers teaching in the afternoon during prep time and other teachers would volunteer to teach during weekends to cover up the lost time.
The mathematics teacher on the other hand explained a departmental strategy that he hopes would help pupils in examination classes.

Interviewer: What strategies will your department employ to mitigate negative effects of COVID-19 which will help learners to prepare adequately for their final examinations?

Head of Mathematics Department: The first thing [to do] will be to look at all the topics that pupils are supposed to learn up to the end of the year. Then we will give them a lot of assignments and homework. We will basically be giving them a lot of work to constantly busy. This way we will be able to compensate for the lost hours of learning.

In relation to the effects of COVID-19 on the rollout of the newly introduced STEM curriculum, all the three participants explained that the programme will be negatively affected. Actually, the Head of Natural Sciences Department explained that the STEM curriculum was expensive to implement because it required expensive material for learning to occur. As such, the bad state of the economy will limit the funding to STEM schools will affect its implementation.

Interviewer: How do you think COVID-19 will affect the rollout of the STEM curriculum in Zambian schools?

Head of Natural Sciences Department: Learning at school offers advantages to pupils of access to facilities and materials that they cannot access at home. Since STEM is more about technology, pupils cannot access it at home. STEM schools require a lot of funding to acuire instructional materials. The schools are likely to face challenges of funding. So, the longer the COVID19 the more severe the effects on education will be.

\section{DISCUSSION AND CONCLUSION}

\section{Discussion}

The results of this study all point to the fact that COVID-19 will have adverse effects on the education sector in Zambia. The reason for this expected trend is largely to the loss of contact hours for secondary school students and lack of e-learning facilities that students could have been using to interact with their teachers. The other reason is that the Examinations Council of Zambia is not likely to postpone the start date of the national examinations if timetables have been prepared. Thus, the short period within which students are supposed to learn and prepare for examinations will possibly affect their performance.

It has also been clearly explained in this study that STEM subjects will be negatively affected in terms of learner performance in the national examinations and 
teachers expect a drop in the performance of Grade 12 students this academic year if the COVID-19 epidemic continues to cause an increase in the number of cases.

Results also seem to suggest that teachers are stepping up their preparedness in containing the negative effects of this epidemic by bringing in pedagogical strategies aimed at ensuring that students in examination classes are adequately prepared for the examinations. It is also a general feeling that implementation of the STEM curriculum in schools that were selected to pioneer its rollout will be adversely affected because the curriculum is expensive to implement and the state of the national economy after COVID-19 will not have the muscle to fully support these schools. It is also expected that donor funding to support the implementation of STEM may reduce because the donor countries have also not been spared by COVID-19 pandemic.

\section{Implications for Further Studies}

This study has established the potential impact of COVID-19 on this year's national examinations for Grade 12 if its effects prolong. The results of this study open up new lines of similar research. It is hoped that other researcher will consider examining the potential impact of COVID-19 on educational planning at national level. The results of this study can further be validated by considering a wider study which would collect both quantitative and qualitative data to give a deeper understanding of the effects of this epidemic. Other studies could focus on how COVID-19 threatens future funding on education by multilateral organizations that are involved in providing educational funds to developing countries. It would also be interesting for researchers to examine the possible reduction of mobility scholarships being offered to Africans to pursue their education in Europe and other parts of the world.

\section{Conclusion}

It has been shown in this study that COVID-19 will have an impact on education provision in Zambia. It remains to be seen how long this epidemic will live but there is hope that Zambian teachers through the ministry of education will devise intervention measures that will benefit all school going children in the country because the future of Zambia lies in the education of the young generation.

\section{ACKNOWLEDGEMENT}

The author would like to thank Chipata Day secondary school for providing trends analysis data for 2018 and 2019 academic years.

\section{REFERENCES}

Chinazzi, M., Davis, J. T., Ajelli, M., Gioannini, C., Litvinova, M., Merler, S., ... Viboud, C. (2020). The effect of travel restrictions on the spread of the 2019 novel coronavirus (COVID-19) outbreak. Science. https:/ / doi.org/10.1126/science.aba9757

Chipata Day Secondary School (2020). Performance analysis report for 2019 school certificate examinations. Chipata, Zambia.

Creswell, J. W. (2017). Educational Research: Planning, conducting, and evaluating quantitative and qualitative research. 4 th edition.

Hopman, J., Allegranzi, B., \& Mehtar, S. (2020). Managing COVID-19 in Low and Middle income Countries. JAMA. https://doi.org/10.1001/ jama.2020.4169

Kraemer, M. U., Yang, C. H., Gutierrez, B., Wu, C. H., Klein, B., Pigott, D. M., ... Brownstein, J. S. (2020). The effect of human mobility and control measures on the COVID-19 epidemic in China. Science. https:/ / doi.org/10.1126/science.abb4218

Sintema, E. J., \& Phiri, P. A. (2018). An investigation of zambian mathematics student teachers' technological pedagogical content knowledge (TPACK). Journal of Basic and Applied Research International, 24(2), 70-77.

Wang, C., Cheng, Z., Yue, X. G., \& McAleer, M. (2020). Risk Management of COVID-19 by Universities in China. https:/ / doi.org/10.3390/jrfm13020036

Wickramasinghe, N. C., Steele, E. J., Gorczynski, R. M., Temple, R., Tokoro, G., Wallis, D. H., \& Klyce, B. (2020). Growing Evidence against Global InfectionDriven by Person-to-Person Transfer of COVID-19. VirolCurr Res, 4(1).

Wu, Z., \& McGoogan, J. M. (2020). Characteristics of and important lessons from the coronavirus disease 2019 (COVID-19) outbreak in China: summary of a report of 72314 cases from the Chinese Center for Disease Control and Prevention. JAMA. https:/ / doi.org/10.1001/jama.2020.2648

Zu, Z. Y., Jiang, M. D., Xu, P. P., Chen, W., Ni, Q. Q., Lu, G. M., \& Zhang, L. J. (2020). Coronavirus disease 2019 (COVID-19): A perspective from China. Radiology, 200490. https:/ / doi.org/10.1148/radiol. 2020200490

\section{http://www.ejmste.com}

